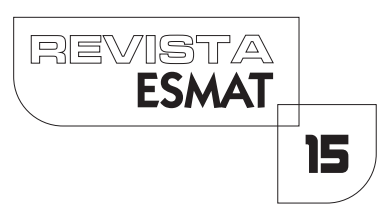

\title{
A MOTIVAÇÃo DA TUTELA JUDICIAL AMBIENTAL
}

\author{
THE MOTIVATION OF THE ENVIRONMENTAL JUDICIAL PROTECTION
}

Marco Anthony Steveson Villas Boas

Mestre em Direito Constitucional e doutorando em Ciências Jurídico-Políticas pela Faculdade de Direito da Universidade de Lisboa (FDUL). Diretor Geral da Escola Superior da Magistratura Tocantinense (ESMAT). Presidente do Colégio Permanente de Diretores das Escolas Estaduais da Magistratura (COPEDEM). Presidente do Tribunal Regional Eleitoral do Tocantins. Ex-Presidente do Colégio de Presidentes dos Tribunais Regionais Eleitorais do Brasil (COPTREL) e do Colégio Permanente dos Corregedores Eleitorais do Brasil (COCEL).

Laudyone Edmailtom dos Santos Arruda

Especialista em Argumentação Jurídica e Teoria da Decisão Judicial. Especialista em Direito Eleitoral e Processo Eleitoral. Assessor Jurídico da Presidência do Tribunal Regional Eleitoral do Tocantins.

\section{RESUMO}

A Constituição do Brasil, de 1988, protegeu o ambiente a partir de uma concepção antropocentrista com viés ecológico, incluindo no mesmo sistema jurídico-político a proteção do ambiente, a partir de direitos fundamentais, sociais, políticos e econômicos, a revelar a opção pelo Estado de Direito Socioambiental, no qual o pluralismo e o multiculturalismo ganharam especial relevo. De outro modo, apesar do avanço normativo e das políticas públicas desenvolvidas no Brasil, o sistema jurídico ainda não alcançou força normativa suficiente para impedir a degradação ambiental, cabendo ao Poder Judiciário a tarefa de solucionar os diversos conflitos entre o direito ao desenvolvimento e o direito ao ambiente equilibrado e saudável, muitas vezes contramajoritariamente, como exige a ponderação que envolve direitos fundamentais, notadamente de minorias, tarefa que exige argumentação e motivação mais laboriosas, com a consciência de que muitas vezes o princípio da razoabilidade se mostra insuficiente para resolver conflitos ambientais, daí a importância da abertura processual para participação popular, a oferecer maior grau de legitimação democrática à construção discursiva da tutela judicial. 
PALAVRAS-CHAVE: Direito ambiental. Decisão judicial. Motivação. Participação popular. Direitos fundamentais.

\begin{abstract}
The Brazilian Constitution, of 1988, protected the environment from an anthropocentric conception with an ecological perspective, including the protection of the environment in the same juridical and political system, from fundamental, social, political and economic rights, revealing the option for the State of Social and Environmental Law, in which pluralism and multiculturalism gained special importance. Otherwise, despite the normative advance and the public policies developed in Brazil, the juridical system has not achieved enough normative force yet to avoid environmental degradation, bringing to the Judiciary the task of resolving the several conflicts between the right to development and the right to the balanced and healthy environment, often not majority, as it is required by the weighting of fundamental rights, especially of minorities, task that requires more laborious argumentation and motivation, with the consciousness that the principle of reasonableness often seems to be insufficient to resolve environmental conflicts, hence the importance of procedural opening for popular participation, to offer a greater degree of democratic legitimacy to the discursive construction of the judicial protection.
\end{abstract}

KEYWORDS: Environmental law. Judicial decision. Motivation. Popular participation. Fundamental rights.

\title{
INTRODUÇÃO
}

A sociedade de risco surgida no processo de industrialização e o agravamento das relações humanas pelo relativismo da pós-modernidade trouxeram diversos problemas para o Direito, que já não tem as respostas adequadas, principalmente acerca do relacionamento ético do homem com a natureza, haja vista o antropocentrismo engendrado pelo humanismo renascentista tê-lo excluído da natureza, colocando-o no centro do universo a partir de então.

Apesar de ser o Senhor de tudo, e cada vez mais consumidor do todo, as relações do homem com a natureza não podem ser pensadas a partir de uma heurística do medo, mas sim fundadas num comportamento ético e responsável, a exigir do Estado uma tutela objetiva de proteção a um bem escasso e finito, e ao mesmo tempo um direito-dever da coletividade, na perspectiva de contemplar a própria sobrevivência do homem no Planeta, e por isso não circunscrita à atual geração, revelando assim um compromisso intergeracional. 
A Constituição do Brasil, de 1988, influenciada pelo Direito Internacional do Ambiente, e pela Constituição da República Portuguesa, de 1976, protegeu o ambiente a partir de uma concepção antropocentrista com viés ecológico, ou antropocentrista alargada, perpassando transversalmente seus diversos títulos e capítulos, incluindo no mesmo sistema jurídico-político a proteção do ambiente a partir de direitos fundamentais, sociais, políticos e econômicos, a revelar a opção pelo Estado de Direito Socioambiental, no qual o pluralismo e o multiculturalismo ganharam especial relevo no viés ecológico, especialmente em seus arts. 21 6, 225, 23 I e 232, dentre outros.

De outro modo, apesar do avanço normativo e das políticas públicas desenvolvidas no Brasil, a Constituição e o arcabouço infraconstitucional ainda não encontram força normativa suficiente para impedir a degradação ambiental, cabendo ao Poder Judiciário a tarefa de solucionar os diversos conflitos entre o direito ao desenvolvimento e o direito ao ambiente equilibrado e saudável, muitas vezes contramajoritariamente, como exige a ponderação que envolve direitos fundamentais, notadamente de minorias, tarefa que exige argumentação e motivação mais laboriosas, com a consciência de que muitas vezes o princípio da razoabilidade se mostra insuficiente para resolver conflitos ambientais.

Nesse contexto, a possibilidade de participação popular na construção do sistema jurídico, até mesmo na atividade jurisdicional, permite o surgimento de uma nova ética na argumentação jurídica, em que a construção discursiva abre espaço à interpretação da Constituição e para o compartilhamento de responsabilidades na proteção do ambiente, na qual a sociedade, o Estado e o Judiciário possam agregar-lhe força normativa com a entrega de uma prestação jurisdicional mais justa e eficaz.

\section{PARA UMA COMPREENSÃO DA NATUREZA JURÍDICA DA PROTEÇÃO DO AMBIENTE}

A compreensão das relações do homem com a natureza demanda sua resconstrução nos diversos períodos da história, inicialmente como essência ordenada e imutável. Concebida no período clássico como concepção de Cosmos - abandonada na Idade Média (354 e I596 d.C.) - levou o homem a conceber a natureza como criação divina, na perspectiva de que Deus tudo criou, e em sua Divina Providência continua a reger as leis de causa e efeito no curso evolutivo do universo, atribuindo ao homem, criado à sua imagem e semelhança, o depositário da dignidade e do poder sobre a natureza, surgindo aí o princípio da supremacia do ser humano na terra, característica marcante do humanismo, no qual finca raízes o antropocentrismo do Período Moderno (1596 a 1850 d.C.), em que a revolução científica afastou o teocentrismo e centralizou no homem a base do universo, a partir da ideia cartesiana de que somente a razão poderia conhecer e compreender o universo, conforme Ariel $\operatorname{Koch}(2013$, p. 31$)$.

Direito Natural, nesse contexto, foi concebido como direito ideal, universal e 
imutável, fundado na valoração do Direito Positivo a partir de um sistema superior de normas ou de princípios que condiciona sua validade, ou seja, seus conteúdos estão atrelados a uma ideia de justiça, de modo a validar apenas as normas que correspondam a esse ideal, cujas referências historicamente construídas se identificam: i) inicialmente, no mundo antigo, com a própria natureza do Universo, ligada à ideia de cosmos (Direito Natural Cosmológico); ii) com Deus, num segundo momento (Direito Natural Teológico); iii) e, no mundo moderno, com a natureza humana ligada à razão (Direito Natural Antropológico), quando o homem, dotado de razão, é o centro do universo, portador de direitos naturais inatos, em oposição à coação jurídica individual.

Todavia, o relativismo da pós-modernidade gerou certos problemas de fundamentação do Direito para o homem e para o ambiente, permitindo a validação de qualquer argumento, tendo em vista que as diversas contradições e contrariedades decorrentes das oposições entre normas e decisões conduzem a uma ideia de que nada é verdadeiro e proporcionam qualquer solução, levando a sociedade à insegurança. Em outras palavras, o Direito mantém suas bases no positivismo jurídico, mas lança mão da fundamentação mais coerente e justificável em determinado momento, sem assumir o relativismo, haja vista o Direito não encontrar chão no terreno movediço do relativo, no qual sucumbiria.

Mas não residiram apenas nisso os males da sociedade moderna, também denominada "sociedade de risco", segundo Ulrich Beck (20।0), um mundo fora de controle, no qual não há nada certo além da incerteza. Beck chama a atenção para as incertezas fabricadas pelo homem, com a velocidade das inovações tecnológicas e respostas sociais céleres, o que fomenta a criação de uma paisagem de risco global, que encampa desde a instabilidade dos mercados e catástrofes ambientais ao terrorismo.

Para ele, a sociedade industrial constituiu terreno fértil para o surgimento da "sociedade de risco", ambiente no qual a ciência e a tecnologia não mais podiam prever e contingenciar os riscos que foram capazes de criar. Observa o autor que essa nova realidade esfarela as fronteiras políticas entre os países, dada a crescente percepção de que se vive num mundo interconectado que está se descontrolando (natureza transfronteiriça dos problemas).

Em seu magistério, a professora Carla Amado Gomes pontua que

A crescente complexidade tecnológica dá, hoje, sustentação a uma sociedade multirriscos, na qual o incremento de bem estar é directamente proporcional ao crescendo de incerteza sobre as consequências das alterações introduzidas. $O$ Homem comporta-se como um "aprendiz de feiticeiro", semeando ventos de mudança que se agigantam em tempestades de consequências imprevisíveis. A técnica e os seus riscos são, simultaneamente, soluções e problemas. (GOMES, 20।4, p. 17). 
Nesse aspecto, serve o alerta que, "em vista do potencial quase escatológico dos nossos processos técnicos, o próprio desconhecimento das consequências últimas é motivo para uma contenção responsável." (JONAS, 2006, p. 63-64). O Estado, portanto, deve atuar segundo o princípio da responsabilidade', em sua dimensão de proteção, o qual exige nova ética para o agir humano, a fim de que os efeitos dele decorrentes sejam compatíveis com a permanência de uma vida humana digna. Ou seja, a sobrevivência humana depende do esforço que esta emprega para cuidar do Planeta e seu futuro.

A perda da identidade do homem com a natureza, em face do modelo econômico produtivo levado a cabo até os dias atuais, foi capaz de produzir danos catastróficos ao equilíbrio do Planeta, como o aquecimento global ${ }^{2}$, de modo a colocar em colapso a qualidade de vida da população atual e gerar incertezas quanto à possibilidade de vida das futuras gerações, ou pelo menos no que toca a uma existência condigna na Terra, situação que levou à jurisdicionalização do ambiente, segundo Carla Amado Gomes (2007, p. 26), rememorando os grandes desastres ambientais do século XX.

François Ost (1995, p. 10) observa que o vínculo do homem com a natureza foi gradativamente se apagando após o Período da Modernidade, levando a natureza à posição de ambiente, o objeto nessa relação em que o homem é dono e senhor, um ambiente que "[...] cedo perderá toda a consistência ontológica, sendo desde logo reduzido a um simples reservatório de recursos, antes de se tornar em depósito de resíduos - em suma, o pátio das traseiras da nossa tecnosfera."

Sob o ponto de vista de Ost (1995, pp. 10-14), o horizonte para a retomada do liame entre o homem e o ambiente está na dialética do vínculo e do limite, dentro do contexto de uma "[...] natureza-projecto: o que fazemos da natureza ela faz de nós [...]", a sugerir "[...] um novo campo de interdependência, que designamos como «meio», e em relação ao qual a questão do «justo» pode ser recolocada com alguma hipótese de sucesso [...]", no intermédio entre o naturalismo e o antropomorfismo, entre o monismo e o dualismo, de caráter nitidamente interdisciplinar, em que o Direito terá a importante missão de "alargar o círculo" e conferir igualdade natural a todos os elementos, e "[...] tratar-se-á de reconhecer-lhe a personalidade e conferir-lhe os direitos subjectivos que lhe são necessários, como o direito de pleitear".

\footnotetext{
' Para Hans Jonas, "O princípio responsabilidade contrapõe a tarefa mais modesta que obriga ao temor e ao respeito: conservar incólume para o homem, na persistente dubiedade de sua liberdade que nenhuma mudança das circunstâncias poderá suprimir, seu mundo e sua essência contra os abusos de seu poder" (JONAS, 2006, p. 23)

${ }^{2}$ CENTRO DE INFORMAÇÃO DAS NAÇÕES UNIDAS RIO DE JANEIRO (UNICRIO). A ONU e o meio ambiente. UNIC Rio de Janeiro - Centro de Informação das Nações Unidas Rio de Janeiro. Rio de Janeiro. Disponível em: < http://unicrio.org.br/a-onu-em-acao/a-onu-e-o-meioambiente/>. Acesso em: 8 Ago. 2017.
} 
A crise conceitual e de lugar do ambiente no Direito da pós-modernidade dá ensejo a diversas construções doutrinárias muito bem pontuadas por Carla Amado Gomes (2007, pp. 103- 107): i) direito subjetivo fundamental ao ambiente, de facetas negativa e positiva, conforme Pereira Reis e Vasco Pereira da Silva, este com mais ênfase na evolução da teoria dos direitos fundamentais, centrados na dignidade da pessoa humana; ii) o ambiente como bem social unitário, dotado de dimensão pessoal, caracterizando-se como direito autônomo, cuja despersonalização e redução nuclear Ihe dá características procedimentais e processuais, a negar-lhe a subjetivação negativa, colocando-o mais próximo das relações de vizinhança do direito de propriedade, ou das relações pertinentes aos direitos de personalidade, segundo Canotilho; iii) direito social, a legitimar os limites ecológicos impostos pela Constituição à liberdade econômica, conforme Rui Medeiros; iv) bem de fruição coletiva, marcado pela "subjetividade plurindividual", a despertar interesse difuso fundamental, por isso procedimental, conforme Colaço Antunes; v) bem jurídico coletivo, cujo interesse difuso, pertinente a um direito fundamental coletivo, lhe confere tutela primacialmente pública, a partir da ideia de dever fundamental, numa realidade complexa de direitos fundamentais pessoais ou patrimoniais específicos e de base auntônoma, no dizer de Jorge Miranda; vi) "direito de solidariedade" ou "direito circular", de interesse comum, na conceituação de Vieira de Andrade, o qual não olvida a característica de dever fundamental, também denominado por Casalba Natais "direitos boomerang", ou direitos deveres, de facetas positiva e negativa, os quais afetam, de alguma forma, o próprio titular.

Ainda que a proteção e a fruição do ambiente decorram de diversas facetas jurídicas do constitucionalismo ocidental, tem significativa importância o dever de proteção do ambiente, alimentado pelo princípio da solidariedade - típico do Estado Social -, a reclamar regimes normativos orientados pelos princípios da universalidade, igualdade, proporcionalidade e reserva da lei.

Tais vertentes principiológicas, de outra forma, servem para garantir outros direitos fudamentais, também sob a perspectiva utilitarista, dependentes do desenvolvimento econômico para ganharem concreção, como ocorre no Continente Americano, externando profundas desigualdades entre os extremos da riqueza do Norte e da pobreza Latina, situações replicadas nos estados nacionais.

\section{O PODER JUDICIÁRIO E A SUPERAÇÃO DA VISÃO REDUCIONISTA IMPOSTA PELO POSITIVISMO NASALVAGUARDA DO AMBIENTE}

Nesse novo limiar, o Direito é chamado a dar respostas para muitas questões ambientais, dentre as quais, a prevenção e diminuição dos danos, a partir da constatação de que o meio ambiente apresenta escassez e finitude, a acender o alerta acerca da própria perpetuação da raça humana no Planeta, a qual possibilitou significativos avanços no sistema jurídico internacional, e, apesar da sua questionável força normativa, peculiares a um sistema "soft law", seu universalismo e simbolismo proporcionaram transformações em inúmeras Constituições ocidentais, possibilitando a construção da 
ideia-força de um estado democrático de direito ambiental, sob a ótica de um antropocentrismo alargado.

Carla Amado Gomes (2007, p. 126) observa que o antropocentrismo alargado decorre da valorização da dignidade do ser humano pela realidade ambiental, sob o ponto de vista de que é um ser cultural, natural e altruísta, com obrigações e responsabilidades perante os seus semelhantes, até mesmo pela preservação dos bens naturais. "A dignidade humana pressupõe, num Estado com preocupações ecológicas, o respeito pela natureza. Por isso se fala de 'antropocentrismo alargado' (extended stewardship ideology)". E numa leitura sistemática da Constituição da República Portuguesa (CRP) chega-se à conclusão de que "o objecto de tutela visado pelo artigo $66^{\circ}$ são os bens ambientais naturais - sem que isso implique o descentramento da tutela ambiental em face do ser humano."

Acentua José Joaquim Gomes Canotilho (20 I I, p. 2 I -22) que essa nova vertente constitucional, fruto da preocupação com a ameaça ao bem-estar da humanidade, causada pelos grandes desastres ambientais e pelo consequente aquecimento do Planeta, constitui-se em considerável avanço do direito do ambiente, que saiu de uma dimensão jurídico-normativa antropocêntrica ${ }^{3}$, ganhando matizes ecológicos desde sua inserção na Constituição da República Portuguesa, mas sem fundamentalismo e sem impor uma ética ambiental transcendente, e não antropicamente centrada. Todos esses fatores contribuíram para o despontar de um estado de direito ambiental.

A Constituição do Brasil, de certo modo, incorporou um pluralismo moderado, ou antropocentrismo alargado, influenciada pela Constituição de Portugal, de 1976, no que se refere à proteção do ambiente, conforme visto alhures, a qual permeou significativa parte do Texto Constitucional. A transversalidade do direito do ambiente na Constituição do Brasil, dessa forma, perpassa os demais subsistemas, principalmente os da cultura, das populações tradicionais e indígenas, além dos subsistemas dos direitos fundamentais, da saúde e da economia, entre outros. Dessarte, não exclui o homem do seu contexto, justamente por essa transversalidade, da qual resulta uma proteção socioambiental em que o homem é beneficiário e responsável pelo ambiente no qual vive. A proteção socioambiental surge na Constituição do Brasil sob a mesma inspiração europeia da ética intergeracional, da qual resulta o principio responsabilidade, no dizer de Hans Jonas (2006, passim), fundamentada na solidariedade intergeracional, decorrente da fraternidade, terceira dimensão dos direitos humanos.

A inserção constitucional dos direitos humanos, notadamente dos povos indígenas e das populações tradicionais, mesclados ao direito do ambiente, contemplados

\footnotetext{
${ }^{3}$ Alguns autores, como Celso Antonio Pacheco Fiorillo, defendem o alinhamento antropocêntrico do direito do ambiente, fazendo sérias críticas ao ecocentrismo. (FIORILLO, Celso Antonio Pacheco Fiorillo. Curso de Direito Ambiental Brasileiro. $2^{\mathrm{a}}$ ed. São Paulo: Saraiva, 200 I, pp. I418).
} 
transversalmente em diversos capítulos, explicita a peculiar "vontade de constituição", visivelmente pluralista, nitidamente influenciada pelo constitucionalismo fraternal, solidário (ANDRADE, 2010 , p. 24I), que tem por diretriz a concreção da igualdade civil e moral de minorias, como verdadeiros trunfos contra a maioria (NOVAIS, 20 I 2, p. 55), centrado na dignidade da pessoa humana, mormente no que se refere à compensação das desvantagens e perdas perpetradas ao longo da história.

Ingo Sarlet e Tiago Fensteiseifer (20 I0, p. 13), no mesmo sentido, entendem que a qualidade ambiental - incorporada num mesmo projeto jurídico-político que agrega as conquistas dos Estados Liberal e Social - integra o conteúdo normativo do princípio da dignidade da pessoa humana, "[... especialmente em razão da sua imprescindibilidade à manutenção e à existência da vida e de uma vida com qualidade, sendo fundamental ao desenvolvimento de todo potencial humano num quadrante de completo bem-estar existencial."

Dessa vertente constitucional, segundo os mesmos autores, emana um Estado Socioambiental de Direito que abarca a tutela dos direitos sociais e ambientais num mesmo projeto jurídico-político para um desenvolvimento do homem dentro de determinados padrões de sustentabilidade, "[...] inclusive pela perspectiva da noção ampliada e integrada dos direitos econômicos, sociais, culturais e ambientais (DESCA)." (SARLET; FENSTEISEIFER, p. I3).

De outro modo, mesmo a proteção constitucional do ambiente em nível elevado de proteção, aliada à legislação infraconstitucional não são suficientes para conter os altos níveis entrópicos decorrentes do processo de desenvolvimento ocidental, sempre a depender de força normativa determinada por políticas públicas efetivas, e da proteção e correção do sistema na via judicial.

Ainda que nos sistemas de comando e controle fundados na utilização da melhor técnica, como o estadunidense, no qual as agências reguladoras têm nos estudos e relatórios de impacto ambiental alguns dos instrumentos para elevado nível de atuação em favor da coletividade, os desvios não escapam da correção pelo "jude made law", ainda que seja para determinar a instauração do regular processo de licenciamento pelos órgãos administrativos.

Assim, espera-se do Poder Judiciário a concretização das normas ambientais no seu sentido lato (norma-princípio e norma-regra ${ }^{4}$ ) por intermédio de seus pronunciamentos cogentes e tendentes à definitividade.

$\bigcirc$ Judiciário então se depara com a corresponsabilidade pelo sucesso do projeto político socioambiental objetivado pela Constituição Brasileira, de 1988. Essa responsabilidade que classicamente competia aos Poderes Executivo e Legislativo passa

\footnotetext{
${ }^{4}$ Segundo Alexy "Toda norma é ou uma regra ou um princípio". (ALEXY, Robert. Teoria dos direitos fundamentais. Tradução de Virgílio Afonso da Silva. 2 ed. 2a tiragem. São Paulo: Malheiros, 2012, p. 91).
} 
a ser compartilhada pelo Judiciário, que se torna responsável por aferir se suas ações estão em conformidade com o projeto arquitetado na Carta Magna, destacando que eventual correção de desvio no conseguimento desse desígnio ocorre após provocação e justamente por meio do processo judicial e seus institutos.

O juiz, nessa perspectiva, não se dedica à mera constatação e aplicação mecânica da lei (função outrora exercida no Estado Liberal) ${ }^{5}$, haja vista que, sob a égide do Estado Democrático, a ciência do Direito centra-se nos critérios de interpretação no âmbito da justificação da decisão judicial com o escopo de estabelecer o limiar entre arbitrariedade e discricionariedade na revelação da norma jurídica para o caso submetido a seu exame.

A lei, portanto, é apenas o ponto de partida, um elemento a ser identificado e reconstruído a partir de sua interpretação contextualizada. É exatamente nesse ponto em que reside a relevância da justificação da decisão judicial - espaço no qual o magistrado externaliza o caminho percorrido na construção da norma jurídica do caso concreto -, porque possibilita à sociedade aferir se a questão submetida ao crivo do Poder Judiciário foi solucionada como determina o próprio Direito posto. Isto é, pela aplicação racional do sistema normativo vigente, sem apelo ao sentimentalismo, demagogia ou critérios atécnicos.

\section{O DEVER DE MOTIVAÇÃO COMO EXPRESSÃO LÓGICA DO ESTADO CONSTITUCIONAL}

O dever de motivar as decisões, não obstante manifesta previsão constitucional ${ }^{6}$, é consectário lógico do Estado Democrático de Direito e dos seus princípios, e ainda que essa exigência não contasse com previsão expressa na Constituição Federal, sua observância decorreria da exegese do art. $5_{-}^{\circ}, \mathrm{LIV}^{7}$, que trata do postulado do devido

\footnotetext{
5 "No Estado Liberal de Direito, os parlamentos da Europa continental reservaram a si o poder político mediante a fórmula do princípio da legalidade, diante da hegemonia do parlamento, o Executivo e o Judiciário assumiram posições óbvias de subordinação; o executivo somente poderia atuar se autorizado pela lei e nos seus exatos limites, e o judiciário apenas aplicá-la, sem mesmo poder interpretá-la; o legislativo, assim, assumia uma nítida posição de superioridade. $\mathrm{Na}$ teoria da separação dos poderes, a criação do direito era tarefa única e exclusiva do legislativo" (MARINONI, Luiz Guilherme. Teoria geral do processo. Curso de processo civil. 3. ed. rev. e atual. São Paulo: Revista dos Tribunais, v. I , 2008, p. 27).

${ }^{6}$ Com a promulgação da EC no 45, de 2004, a Constituição Brasileira, de 1988, reforçou o imperativo da motivação da decisão ao prever expressamente no inciso IX do art. 93 que "todos os julgamentos do Poder Judiciário serão públicos, e fundamentadas todas as decisões, sob pena de nulidade (...)".

${ }^{7}$ Constituição Federal, de 1988: art. $5^{\circ}$ (...) "LIV - ninguém será privado da liberdade ou de seus bens sem o devido processo legal."
} 
processo legal (due process of law).

A exigência de motivação, ou seja, de fundamentação, encerra a ideia de composição mínima de um processo justo e constitui garantia fundamental do jurisdicionado contra possíveis arbitrariedades do Estado. O dever de motivação, dessarte, tem por escopo tornar visíveis as razões de decidir do julgador, revelando os critérios de interpretação utilizados na contextualização das normas incidentes e a identificação dos fatos relevantes da causa. Demais disso, a garantia constitucional da motivação da decisão judicial "constitui uma primeira limitação ao poder dos juízes", por isso, as "razões da decisão devem ser expostas com clareza, coerência e congruência, visando à perfeita compreensão de todos os pontos controvertidos da demanda." (AMORIM, 20I I, p. 84I).

Por corroborar um princípio tão dadivoso, a própria Lei Maior - fugindo de sua linha tradicional de estabelecer direitos e deveres -, previu sanção de nulidade para as decisões judiciais imotivadas (DIDIERJUNIOR; BRAGA; OLIVEIRA, 20I5, p. 3।4).

Preocupado em atender à suficiência do postulado em questão, o Código de Processo Civil, além de replicar o dispositivo constitucional, cuidou de elencar situações em que não considera fundamentada a decisão judicial, exigindo do órgão jurisdicional maior cuidado e capricho na fundamentação (NEVES, 20 I 6, p. I26).

Em sua visão tradicional, o princípio da motivação das decisões foi concebido como garantia técnica do processo, cuja finalidade consiste em propiciar às partes identificar os reais motivos que conduziram o magistrado a decidir daquela forma, como também aferir se as teses e provas reputadas relevantes foram consideradas no julgamento final. Nesse aspecto endoprocessual, a motivação da decisão possibilita tanto a fiscalização da atuação do julgador quanto o manejo adequado dos meios de impugnação de decisão pela parte prejudicada. Isso porque o provimento jurisdicional desmotivado obviamente obstaculiza o contraditório e a ampla defesa, uma vez que a parte tida por prejudicada encontrará severa dificuldade na formulação ajustada das razões de seu inconformismo. Ademais, a ausência de externalização dos fundamentos da decisão judicial dificulta a compreensão da controvérsia pelas instâncias recursais e, consequentemente, torna nebuloso o exame da legalidade da decisão vergastada ${ }^{8}$.

Modernamente, o princípio da motivação se revela como garantia de ordem política ou da própria jurisdição. Nesse prisma, o dever de fundamentação tem como destinatário todo e qualquer indivíduo, porquanto não se destina apenas aos da relação

\footnotetext{
8“Num primeiro momento é voltada ao sucumbente, que sem conhecimento das razões da decisão não teria condições de elaborar o seu recurso, porque ninguém pode impugnar de forma específica uma decisão sem conhecer seus fundamentos. Num segundo momento a fundamentação se mostra imprescindível para que o órgão jurisdicional competente para o julgamento do recurso possa analisar o acerto ou equívoco do julgamento impugnado." (NEVES, 2016, p. 125).
} 
processual. É o que doutrinariamente se denomina de função "exoprocessual" ou "extraprocessual", pela qual a fundamentação constitui ferramenta de legitimação política e de limitação do poder judicial, porque viabiliza o controle da decisão por toda a sociedade. Por essa via difusa da democracia participativa, o povo, em cujo nome a decisão judicial é proferida, afere em concreto tanto a imparcialidade e conhecimento de causa do magistrado quanto à legalidade e justiça de seu veredito (DIDIER JUNIOR; BRAGA; OLIVEIRA, 20।5, p. 315).

No Estado Democrático é importante que se saiba como os juízes decidem, porquanto a legitimação e controle de seus pronunciamentos pela sociedade perpassam, necessariamente, pelo princípio constitucional da motivação e da publicidade das decisões judiciais'. Sob a jurisdição do Estado Constitucional, o exercício de poder só será considerado legítimo à medida que seus órgãos atuarem como delegatários do povo - legítimo detentor do Poder (Constituição Federal, art. $1^{\circ}$, parágrafo único) - nos espaços juridicamente pré-delimitados na Lei Maior.

A participação do povo não fica reclusa apenas à formação da vontade estatal por meio do sistema legiferante, uma vez que reside também na fiscalização e controle dos atos praticados pelo Poder Público, direta ou indiretamente, sendo a motivação das decisões estatais genuíno aparelho viabilizador dessa sindicância popular.

Para o atendimento do dever de motivação, não é suficiente que o magistrado resolva o litígio, antes disso lhe compete exteriorizar os motivos norteadores de sua decisão "para que convença as partes e toda a sociedade de que aquela foi a melhor solução e de que usou seus poderes devidamente, e só dessa forma a prestação jurisdicional será efetivamente atendida e controlável." (AMORIM, 20 I I, p. 84I).

Essa garantia fundamental do cidadão corresponde a uma obrigação do magistrado, que na condição de representante do poder deve concretizá-la em seus pronunciamentos, a fim de dar concreção aos postulados jurídicos que sustentam o próprio Estado Democrático.

A tutela jurisdicional na complexa sociedade tecnológica - sociedade de risco dedica-se ao resguardo de novos direitos, em conflito e em expansão, disciplinados por normas abertas as quais exigem do julgador uma interpretação criativa tanto para reconhecê-los quanto para concretizá-los.

O Direito Ambiental, nesse perfilhar, influenciado pela universalização e simbolismo do Direito Internacional do Ambiente, expõe-se como um direito em constante

\footnotetext{
9"A garantia de motivação das decisões judiciais tem por fim assegurar uma justificação política para as decisões. Sim, porque só se pode considerar como legítima do ponto de vista constitucional uma decisão que possa ser submetida a alguma espécie de controle (seja tal controle proveniente das partes, do próprio judiciário ou da sociedade), e tal controle só é possível se a decisão judicial tiver sido fundamentada." (CÂMARA, Alexandre Freitas. Lições de Direito Processual Civil. Vol. I. I 8 ed. São Paulo: Lumen Juris, 2008, p. 56).
} 
evolução e mutação, cuja direção não se volta preponderantemente ao passado (com prescrições sancionatórias ao agressor dos bens ambientais), já que também se ocupa essencialmente com o futuro (preservação do meio ambiente sadio para a geração presente e às futuras). E, com obviedade, sua normatividade, muitas vezes acanhada e insuficiente, é caracterizada nitidamente por sua faceta principiológica.

Nesse contexto, o juiz depara-se com a árdua missão de interpretar o direito positivado e de levar a cabo sua contínua adaptação às contemporâneas e plurais realidades sociais na procura do justo. A decisão judicial, nessa conjuntura, muitas vezes preenche vazios normativos e dá à lei interpretação contextualizada e adequada, segundo os critérios da razão prática e as concepções gerais de justiça consolidadas na comunidade em que é inserida (ALEXY, 20।3, p. 39-40).

Não se pode olvidar que as decisões de cunho ambiental, sobretudo quando favoráveis ao Meio Ambiente, não raramente são criticadas sob a pecha de suposta irracionalidade, sendo reputadas como um apelo ao emocionalismo ou demagogia no trato do tema. Dessarte, diante de juízos de valor, com maior razão deve o magistrado lançar mão das teorias de argumentação jurídica, a fim de comprovar a racionalidade da motivação dos seus vereditos pela declinação de argumentos íntegros e coerentes, e, consequentemente, concretizar a tutela que se espera do Judiciário.

Evidentemente, a construção da norma justa para o caso concreto não constitui uma tarefa fácil. Dada a natureza multidisciplinar do Direito Ambiental, o conhecimento das leis e princípios, por si, não asseguram ao juiz o substrato necessário e suficiente à solução justa para o litígio.

Nesse sentido, a Jurisdição Ambiental aponta para a necessidade de o Direito dialogar com outras áreas do conhecimento para então obter subsídios capazes de contribuir para o incremento da qualidade da tutela ambiental.

Tão importante quanto a motivação da tutela ambiental é a abertura do espaço em que esta se desenvolve. São os dois lados de uma mesma moeda. Ora, consistindo o processo judicial no instrumento hábil à concretização de direitos e garantias fundamentais, é importante propiciar a participação alargada, dialética e isonômica dos indivíduos que dele participam para a formação do alicerce da construção do provimento final.

Há muito o Estado-Juiz não detém o monopólio da interpretação do ordenamento jurídico-constitucional, sendo reconhecida ao destinatário da norma a participação ativa

\footnotetext{
10 "O destinatário da norma é participante ativo, muito mais ativo do que se pode supor tradicionalmente, do processo hermenêutico. Como não são apenas os intérpretes jurídicos que vivem a norma, não detêm eles o monopólio da interpretação da Constituição" (HABERLE, Peter. Hermenêutica Constitucional, A sociedade aberta dos intérpretes da Constituição: Contribuição para a Interpretação Pluralista e 'Procedimental' da Constituição. Trad. Gilmar Ferreira Mendes. Porto Alegre: Ed. Sergio Antonio Fabris, 1997, p. 15.
} 
no processo hermenêutico ${ }^{10}$.

Peter Harbele (1997, p. 13) já expunha o clamor do Estado Democrático de Direito por uma sociedade aberta e atuante, bem como uma teoria discursiva do Direito, residindo na construção participada a legitimidade jurídico-social da norma jurídica.

As demandas envolvendo bens ambientais ultrapassam os interesses individuais, porquanto o direito envolvido - de cariz fraternal - interessa à coletividade. Aliás, não foi por outra razão que a Constituição do Brasil, em seu art. 225, atribuiu a responsabilidade de defender e preservar o Meio Ambiente ao Poder Público e para toda a sociedade.

No ambiente procedimentalmente programado, fomentar e administrar a participação amplificada é incumbência do juiz, que deve suportar também a carga de uma busca correta dos meios para o atingimento da finalidade jurisdicional.

$\bigcirc$ Código de Processo Civil, de 2015, atento ao desejo constitucional de democracia participativa, previu instrumentos de abertura do Judiciário à participação social integrada". As audiências públicas e o amicus curiae são exemplos de institutos que o magistrado pode se valer para criar o espaço público necessário à participação da comunidade, e assim conferir maior legitimidade ao seu julgamento. Isso porque "Se a visão do mundo capaz de legitimar o direito não é pré-existente, significa que somente um poder comunicativo, desenvolvido em uma práxis argumentativa inserida em um espaço público determinado será capaz de gerar o Direito de forma legítima." (BOTELHO, 2010, p. 149).

$\mathrm{Na}$ esfera de incidência do Direito Ambiental, desaconselha-se o isolamento do magistrado em seu gabinete, na solidão do Direito, quando do processo de tomada de decisão. Antes disso, à vista do desiderato do Estado Socioambiental, compete a ele afiançar o espaço aberto à participação inclusiva dos atores sociais por meio do

" CPC/20 I 5: "Art. 138. O juiz ou o relator, considerando a relevância da matéria, a especificidade do tema objeto da demanda ou a repercussão social da controvérsia, poderá, por decisão irrecorrível, de ofício ou a requerimento das partes ou de quem pretenda manifestar-se, solicitar ou admitir a participação de pessoa natural ou jurídica, órgão ou entidade especializada, com representatividade adequada, no prazo de 15 (quinze) dias de sua intimação. (...) Art. 983. O relator ouvirá as partes e os demais interessados, inclusive pessoas, órgãos e entidades com interesse na controvérsia, que, no prazo comum de 15 (quinze) dias, poderão requerer a juntada de documentos, bem como as diligências necessárias para a elucidação da questão de direito controvertida, e, em seguida, manifestar-se-á o Ministério Público, no mesmo prazo. § ${ }^{\circ}$ Para instruir o incidente, o relator poderá designar data para, em audiência pública, ouvir depoimentos de pessoas com experiência e conhecimento na matéria. (...) Art. 1.038. O relator poderá: I solicitar ou admitir manifestação de pessoas, órgãos ou entidades com interesse na controvérsia, considerando a relevância da matéria e consoante dispuser o regimento interno; II - fixar data para, em audiência pública, ouvir depoimentos de pessoas com experiência e conhecimento na matéria, com a finalidade de instruir o procedimento;" 
procedimento, com atalhamento das intervenções impertinentes e com a filtragem dos argumentos $^{12}$, a fim de que sejam levados em consideração no processo decisório apenas aqueles considerados íntegros e sujeitos à aferição do critério de validade e de coerência ao sistema jurídico.

Na ação comunicativa habermasiana, os argumentos também formam os motivos que dão suporte à integração da realidade no processo de construção racional da decisão, fundamentada no alento do melhor deles, além, é claro, de informar um novo agir social, com a ampliação da consciência coletiva (efeito performático) ${ }^{13}$.

A teoria habermasiana sugere a abertura da Corte Constitucional à participação dilatada dos interessados, com a criação de uma esfera pública que favoreça a ampla movimentação de informações e argumentos, operando o Tribunal como fiador do "desenvolvimento harmônico dessa rede de liberdades comunicativas capaz de levar a construção de uma decisão fundamentada unicamente na força do melhor argumento." (BOTELHO, 2010, p. 17I).

Evidentemente que o papel da Jurisdição Ambiental Constitucional, nesse intermédio, não fica relegado ao de mera tutoria da esfera pública, até mesmo porque a ela incumbe dar a última palavra sobre interpretação da Constituição, a fim de "preservar a relação existente entre o programa normativo (interpretação constitucional) e o âmbito normativo (realidade constitucional)" (BOTELHO, 20 I 0, p. 173). Nesse tocante, o sistema de princípios constitui importante vetor desse papel conformador, sobretudo na seara do Direito Ambiental.

De tessitura constitucional, os princípios do meio ambiente ressoam em toda a legislação ordinária ambiental, orientando sua interpretação e aplicação. No constitucionalismo contemporâneo, os princípios deixaram de ser meras fontes informativas e de integração à espécie de norma jurídica, dotados, portanto, de notória densidade normativa. Ainda, é exatamente na utilização dos princípios para fundamentar

\footnotetext{
12 " (...) a abertura proposta por Habermas tem limites naturais e estruturais, os quais não podem ser olvidados, sob pena de eternização do procedimento. (...) Essa participação livre, todavia, não pode ser desvirtuada, tornando o procedimento um infindável jogo de argumentações, sem qualquer previsibilidade de um ponto de chegada." BOTELHO, Marcos César. A legitimidade da jurisdição constitucional no pensamento de Jürgen Habermas. São Paulo: Saraiva, 20 I 0, p. 174

13 "O próprio caráter artificial do Direito, descrito por Habermas, serve de fundamento para a argumentação acima, pois as normas do Direito, sendo artificiais "formam uma camada de normas de ação produzidas intencionalmente, reflexivas, isto é, aplicáveis a si mesmas". E essa produção intencional (ou reflexiva) exige justamente uma vinculação dos atores sociais à forma de ação performativa, pois somente assim poder-se-á falar em normas produzidas de forma legítima e democrática." (BOTELHO, Marcos César. A legitimidade da jurisdição constitucional no pensamento de Jürgen Habermas. São Paulo: Saraiva, 20 I0, p. 169).
} 
decisões judiciais que se apoia a crítica quanto à suposta existência de subjetivismo do julgador - dado o alto grau de abstração e eleva carga axiológica daqueles ${ }^{14}$-, fator este que reclama do julgador, como dito alhures, maior esforço para revelar a racionalidade e coerência de seu veredito, sob pena de este padecer de nulidade.

Em se tratando de demanda de natureza ambiental, a tensão entre princípios, sobretudo, é problema rotineiramente submetido à avaliação do julgador.

Objetivando aclarar a fundamentação das decisões de natureza ambiental, e em busca de se construir uma resposta íntegra, coerente e coesa para o caso levado a exame judicial, importa realçar a dimensão da técnica de ponderação de princípios.

Em sua teoria sobre direitos fundamentais, Robert Alexy (2012, p. 85) destaca a importância da distinção entre regras e princípios à utilização da ponderação, porque "sem ela não pode haver nem uma teoria adequada sobre as restrições a direitos fundamentais, nem uma doutrina satisfatória sobre colisões, nem uma teoria suficiente sobre o papel dos direitos fundamentais no sistema jurídico". Essa distinção compõe a "a estrutura de uma teoria normativo-material dos direitos fundamentais e, como isso, um ponto de partida para a resposta à pergunta acerca da possibilidade e dos limites da racionalidade no âmbito dos direitos fundamentais".

Alexy (2012, p. 92-93) observa que a diferença entre princípios e regras fica mais bem delineada nos casos de tensão entre princípios e conflitos entre regras. Um elemento comum entre colisão entre princípios e conflitos entre regras reside no "fato de que duas normas, se isoladamente aplicadas, levariam a resultados inconciliáveis entre si, ou seja, a dois juízos concretos de dever-ser jurídico contraditórios". Contudo, distinta é a forma em que conflitos e colisões são resolvidos, uma vez que "Conflitos entre regras ocorrem na dimensão da validade, enquanto as colisões entre princípios visto que só princípios válidos podem colidir - ocorrem, para além dessa dimensão, na dimensão do peso."

Dito de outro modo, quando uma regra conflita com outra, a solução se dá pela invalidação de uma e aplicação da outra ou, ainda, pela introdução de uma cláusula de exceção. Diferentemente disso, o caso de colisão de princípios se resolve pelo sopesamento, pela aferição, no caso concreto, do peso dos princípios colidentes.

14 “(...) no direito brasileiro temos vivido momentos de prevalência do puro subjetivismo dos julgadores. Um dos fatores que têm estimulado essa postura por parte de juízes e tribunais é a utilização indiscriminada e descontrolada de princípios, mesmo existindo no ordenamento jurídico regras claras e inequívocas e passíveis de aplicação na decisão dos casos concretos." (GOUVEIA, Lúcio Grassi de. O dever de fundamentação das decisões judiciais e o novo código de processo civil brasileiro. In: CARVALHO FILHO, Antônio; SAMPAIO JR., Herval. (Orgs.). Os juízes e o novo CPC. Salvador: JusPodivm, 2017, pp. 263-264). 
Enquanto a incidência da regra segue a máxima do "tudo ou nada", na qual uma das normas é invalidada, a tensão entre princípios não se resolve pela exclusão definitiva de um dos direitos envolvidos. Verificada a tensão, um dos princípios irá ceder ao outro de acordo com as circunstâncias do caso concreto, determinantes à aferição do "peso" dos direitos tensionados, sem que isso, contudo, implique aniquilação do princípio alijado do ordenamento jurídico. Como mandamentos de otimização, os princípios "são caracterizados por poderem ser satisfeitos em graus variados e pelo fato de que a medida devida de sua satisfação não depende somente das possibilidades fáticas, mas também das possibilidades jurídicas". (ALEXY, 20 I 2, p. 90).

Ao tratar do fato do pluralismo e direitos de minorias no sistema democrático, Ronald Dworkin (2002, passim) evidencia que a democracia não se traduz pela imposição dos direitos da maioria, construindo a teoria dos trunfos a partir da hipótese de que as minorias não podem ser excluídas do processo democrático, pois todos têm direito a uma vida boa e à felicidade.

Assim, é preciso ir mais além e buscar nos métodos de interpretação teleológico, histórico e sistemático, sem perder de vista a unicidade dos "preceitos e princípios jurídicos que the correspondem." (MIRANDA, 20 I I , p. 654), a partir da ideia-força de que direitos fundamentais se interpretam numa perspectiva jurisdicional contramajoritária, conforme observa Jorge Reis Novais (20 I2, p. 27).

Jorge Reis Novais (2010, p. 3 19-325) não deixa de ver dificuldades de sustentação da teoria dos trunfos em defesa dos direitos sociais; e, como o próprio autor afirma, é necessário perquirir sobre a natureza fundamental desses direitos; "garantias de Estado de Direito" "[... . protegem o indivíduo do Estado e fazem-se valer, se for o caso, contra a decisão democrática, os poderes instituídos, a maioria."

Por outro viés, Alexandra Aragão (2012, p. 65) conjuga os princípios da "proibição do retrocesso social" com o do "nível mais elevado de proteção ecológica" para defender a tese do "não retrocesso ambiental", o qual se aplicaria em raras situações, tendo em vista a dificuldade de ponderações de valores quando a própria existência da geração atual se encontra em risco, seja pela fome, miséria ou outros fatores, e ela própria reconhece que "apesar de podermos pensar que o objecto de protecção do princípio da proibição do retrocesso social - o Homem - é mais digno, mais nobre ou mais importante do que o objecto de protecção do retrocesso ambiental sinteticamente o Planeta Terra - pensamos que esta é uma conclusão precipitada. [...]", o que seria, segundo ela, uma conclusão simplista e redutora.

A natureza procedimental da proteção do ambiente, a depender de ações judiciais específicas para a efetivação da proteção normativa, a exemplo da ação civil pública e da ação popular no Direito Brasileiro (Leis n_ 7.347, de 1985, e 4.717, de 1965), evidencia com maior relevo as argumentações procedimentalistas no sistema judicial, a propiciar a construção discursiva e democrática da decisão. 


\section{APONDERAÇÃO DE PRINCÍPIOS}

No Sistema Constitucional Brasileiro não existem direitos absolutos, tampouco primazia absoluta e hierarquia de um direito sobre outro (CANOTILHO, 2003, p. I. I 83 e I.224- I.226). Acomoda, portanto, a existência harmoniosa das liberdades; e a ponderação surge como técnica adequada à superação dos antagonismos para definir qual dos direitos deve preponderar no caso concreto.

○ juízo de ponderação está intimamente ligado ao princípio da proporcionalidade; exige que a prevalência de um direito sobre outro seja útil à resolução do problema e não exista alternativa menos gravosa para o atingimento do resultado pretendido, rejeitando, desse modo, toda intervenção que impõe ao direito alijado ônus intolerável e desproporcional. Por isso mesmo, a ponderação de princípios colidentes ocorre sempre num caso concreto - o que Alexy (2012, p. 96) denomina de precedência condicionada -, considerando-se as circunstâncias que lhe são peculiares, motivo pelo qual usualmente se afirma que "a solução desses conflitos há de se fazer mediante a utilização do recurso à concordância prática (...), de modo que cada um dos valores jurídicos em conflito ganhe realidade”. (MENDES; BRANCO, 20। 4, p. 240).

Embora inexista um critério de ponderação válido em termos abstratos, há de se relevar a possibilidade de se obter um precedente à solução de demandas futuras, em que será admissível afiançar qual dos direitos tenderá a prevalecer sobre outros, quando verificadas as mesmas condições fáticas que ensejaram aquele julgado específico.

No exame de ponderação, quanto maior for o grau de intervenção em determinado direito fundamental, mais expressivos e relevantes devem ser os argumentos que lhe dão sustentação (MENDES; BRANCO, 20।4, p. 24I). Isso quer dizer que a técnica de ponderação exige do julgador fundamentação criteriosa e consistente que leve em conta todos os argumentos capazes de justificar racionalmente o grau de afetação de um princípio e consequente afastamento de outro. Nesse contexto, Alexy (2012, p. I7I) destaca que

Aquele que afirma que uma afetação muito intensa só pode ser justificada por meio de um grau muito alto de importância da satisfação do princípio colidente ainda não diz quando esta afetação muito intensa e quando esse alto grau de importância estão presentes. Mas ele diz o que deve ser fundamentado para se justificar o enunciado de preferência que representa o resulta do sopesamento: enunciados sobre graus de afetação e importância. Os argumentos que podem ser utilizados na fundamentação desse tipo de enunciado não são relacionados especificamente ao sopesamento. É possível levar em consideração qualquer argumento típico da argumentação jurídica. 
Acrescenta ainda que "Uma tal resposta pode ser fornecida pelo modelo de sopesamento baseado na teoria dos princípios, na medida em que ele vincula a estrutura formal do sopesamento a uma teoria da argumentação jurídica que inclui uma teoria da argumentação prática geral." (ALEXY, 20 I2, p. 167).

Ao lado disso, no sopesamento do grau de importância dos direitos fundamentais em jogo, não se pode olvidar que a proteção do ambiente, sob o ponto de vista dos direitos fundamentais, como direito-dever, envolve peculiaridades como escassez e finitude dos recursos naturais, a colocar em risco não apenas a atual geração, mas principalmente as futuras gerações, que ainda não se encontram presentes para defenderem seus direitos.

Desse modo, o permanente conflito entre o direito fundamental ao ambiente e o direito fundamental ao desenvolvimento deve ser solucionado com a temperança necessária para que o desenvolvimento aconteça em diversos planos, e não apenas no econômico, a fim de que o desenvolvimento sociocultural e o etnodesenvolvimento, típicos do pluralismo e do multiculturalismo, não sejam negados às minorias, assim como os direitos das gerações futuras de terem acesso aos recursos naturais, e possam ter vida saudável proporcionada por um ambiente preservado e equilibrado.

O Supremo Tribunal Federal (STF), em ações de natureza ambiental, tem lançado mão do processo da ponderação como base argumentativa para conformar, por exemplo, o direito ao meio ambiente equilibrado e à livre iniciativa econômica, frequentemente submetidos ao julgamento da Corte. Nesse sentido, o julgamento da Arguição de Descumprimento de Preceito Fundamental (ADPF) I 01 , por meio da qual se discutia se decisões judiciais que autorizavam a importação de pneus usados (princípio econômico da livre iniciativa) vulneravam a garantia constitucional ao meio ambiente equilibrado, oferece exemplo do uso do juízo de ponderação pela Suprema Corte. Naquela assentada de julgamento, o STF decidiu, nos termos do voto da ministra Carmen Lucia - relatora da ADPF -, que a fatura econômica não poderia ser resgatada com a saúde humana nem com a deterioração do ambiente para a presente geração e às futuras, dando prevalência ao direito ao meio ambiente equilibrado.

Note-se que a conclusão a que chegou a Suprema Corte não se deu por mera opção, mas como decorrência do processo dialético estabelecido entre os participantes em busca da construção da melhor decisão e com fundamento no projeto políticoeconômico erigido pela própria Constituição Federal. Em interessante trecho de seu voto, a ministra-relatora, Carmen Lucia, afirma que a ponderação entre os valores constitucionais envolvidos deve ser efetivado e solucionado com fundamento na Lei Maior, porque ela é reveladora do fim político esquadrinhado pela sociedade para "aperfeiçoar os objetivos de hoje na perspectiva histórica do devir". Chamando a atenção à responsabilidade pelo sucesso do Estado Democrático pretendido pela Constituinte, de 1988, vaticinou que a "Constituição é mais que dever ser, é também o que é feito ser e o que deverá ser. Informa e conforma o agir da sociedade agora para a 
proximidade histórica que com ela ou a partir dela poderá ser ${ }^{15}$."

A decisão judicial, ainda que fundamentada unicamente em princípios, não pode ter como critério único a preferência subjetiva do julgador. A ponderação alexyana, nesse tocante, traz um encargo maior de argumentação à medida que impõe ao julgador a obrigação de justificar seus parâmetros decisórios, com a exposição das premissas fáticas e jurídicas que dão sustentação aos argumentos declinados. É exatamente nesse ponto que reside a controlabilidade das decisões judiciais, haja vista que a exposição das premissas dos argumentos permite aos interessados identificar a (in)validez da linha argumentativa, bem como a (in)existência de falhas do ato decisório, consubstanciadas na conclusão decisória por algo não explicado, ou ainda na utilização incorreta de argumentos colhidos de precedentes que não se sustentam diante de um novo caso concreto.

Sob a égide da atual Legislação Processual Civil, que objetiva a implantação do sistema de precedentes no Direito Brasileiro, como necessidade de segurança jurídica e previsibilidade das decisões, o exame de ponderação deve ser levado a efeito com a apreensão de todos os aspectos envolvidos na complexa tensão entre os princípios envolvidos. Daí a importância de se conferir efetividade ao postulado da participação pública nas decisões de tutela ambiental ${ }^{16}$, sobretudo nos novos direitos surgidos na sociedade pós-moderna, como o direito ao ambiente equilibrado. Essa abertura "à participação dos interessados no processo de construção das decisões é capaz de enfrentar de maneira legítima o desafio de tornar essa linguagem vaga em respostas democráticas e efetivas aos problemas sociais." (BOTELHO, 20 I0, p. I72).

\footnotetext{
${ }^{15}$ BRASIL. Supremo Tribunal Federal. Arguição de Descumprimento de Preceito Fundamental $n$. I0 I/DF. Relatora: Min. Cármen Lúcia Antunes Rocha. Publicado no DJ de 4/6/20 I 2. Disponível em: <http://redir.stf.jus.br/paginadorpub/paginador.jsp?docTP $=A C \& d o c I D=629955>$. Acesso em 15 ago. 2017.

16 "A participação pública em matéria ambiental, no entanto, não se limita aos campos tradicionais da atuação política, como é o caso do legislativo e do administrativo. $\bigcirc$ mesmo caráter participativo também se verifica no âmbito judicial, especialmente quando estiverem em jogo questões de espectro coletivo como, por exemplo, nas ações civis públicas voltadas ao controle judicial de políticas públicas ou mesmo no campo da jurisdição constitucional, por meio de ações diretas de inconstitucionalidade etc. (...) a criação e o aprimoramento de mecanismos capazes de propiciar a participação pública no âmbito dos três poderes republicanos asseguram maior controle social sobre as atividades públicas. Isso, por certo, ganha relevância em questões que envolvam direitos fundamentais, como é o caso da proteção ambiental." (SARLET, Ingo Wolfgang; FENSTERSEIFER, Tiago. Princípios do direito ambiental. São Paulo: Saraiva, 20 I 4, p. I l 8).
} 


\section{A UTILIZAÇÃO DO CONHECIMENTO CIENTÍFICO NA MOTIVAÇÃO DA TUTELAAMBIENTAL}

Obviamente a decisão judicial de viés ambiental não deve ficar relegada apenas ao discurso jurídico. Antes disso, a racionalidade daquela se comprova não apenas no exame de coerência dos argumentos com determinadas regras legais (princípios, textos legais, doutrina e precedentes jurisprudenciais), mas também com a apropriação de todo o conhecimento científico produzido em torno do tema, mormente em razão de o nosso sistema jurídico seguir o modelo de comando e controle.

Nessa perspectiva, os argumentos produzidos cientificamente, apesar de não serem vinculativos nos casos em que remanescem dúvidas sobre danos futuros, contribuem para a formação de um juízo de previsibilidade acertada, porquanto possibilitam ao juiz fazer inferências sobre o impacto ambiental presente e futuro com mais segurança.

Assim, ocorre, por exemplo, na concreção do princípio da prevenção, que opera no sentido de antecipar a ocorrência do dano ambiental na sua origem, evitando que este ocorra. Entretanto, sua aplicação "transporta a ideia de um conhecimento completo sobre os efeitos de determinada técnica e, em razão do potencial lesivo já diagnosticado, o comando normativo toma o rumo de evitar danos já conhecidos" (SARLET; FENSTERSEIFER, 20 |4, p. 160).

Ao invocar o princípio em comento, na maior parte das vezes o juiz estará orientado pelo conhecimento técnico produzido nos autos, remanescendo, no entanto, quando insuficiente ou duvidoso, certa margem de discricionariedade para solucionar casos difíceis, situações que demandam motivação clara e consistente, haja vista o conhecimento científico muitas vezes não se apresentar suficiente para esclarecer e proporcionar segurança para a decisão de maior grau de complexidade, mormente em situações de maior risco que demandam a aplicação do princípio da precaução.

Como bem esclarece Carla Amado Gomes (2007, p. 293), o que muda em relação à prevenção "[...] não é a forma de abordagem das questões ambientais - sempre preferencialmente preventiva -, mas apenas os meios, concretamente em razão da introdução de parâmetros técnicos no processo de decisão, com vista à gestão da incerteza, i. e., à minimização/evitação dos riscos.

Ingo Wolfgang Sarlet e Tiago Fensterseifer (20 I4, p. 164), de igual modo, observam que "diante da dúvida e da incerteza científica a respeito da segurança e das consequências do uso de determinada substância ou tecnologia, o operador do sistema jurídico deve ter como fio condutor uma postura precavida". Dessarte, o juiz, ao se deparar com tal situação nos autos, deve interpretar "os institutos jurídicos que regem tais relações sociais com a responsabilidade e a cautela que demanda a importância existencial dos bens jurídicos ameaçados (...), inclusive em vista das futuras gerações."

Evidente, pois, nesse ponto, o diálogo da ciência do direito com as outras áreas do conhecimento na busca da construção de uma decisão judicial mais justa, fazendo valer a técnica constitucional de proteção jurídica objetiva, com raízes subjetivas, a reclamar o direito-dever do Estado e da sociedade em relação ao ambiente. 


\section{CONCLUSÃO}

As decisões judiciais devem exprimir a confiança no Estado Democrático. A confiabilidade no Poder Judiciário, na condição de responsável pela pacificação social, passa necessariamente pela legitimação de seus pronunciamentos no seio da sociedade em que é inserida.

A motivação racional da tutela ambiental, portanto, assume salutar meio de transformação social à medida que a sociedade atingida se sente persuadida à sua observância, não apenas por seu poder de império, mas também pelo convencimento que dela se pode extrair. Assim, a tutela ambiental leva a sociedade à reflexão sobre os impactos de suas ações quanto ao meio ambiente, ampliando a consciência coletiva, e orientando um novo agir social mais integrativo e sensível na sua relação com o meio ambiente.

Nesse contexto, o juiz desempenha papel fundamental na sociedade de risco no que diz respeito à formação de uma esfera pública ecológica, por meio da decisão judicial de construção participada, conectada ao reconhecimento do meio ambiente como valor caro à humanidade.

\section{REFERÊNCIAS}

ALEXY, Robert. Teoria da argumentação jurídica: a teoria do discurso racional como teoria da fundamentação jurídica. Trad. Zilda Hutchinson Schild Silva. $3^{a}$ ed. Rio de Janeiro: Forense, 2013.

Teoria dos direitos fundamentais. Tradução de Virgílio Afonso da Silva. $2^{\mathrm{a}}$ ed. 2a tiragem. São Paulo: Malheiros, 2012.

AMORIM, Letícia Balsamão, Motivação das decisões judiciais. In: TORRES, Ricardo Lobo et al. (Org.). Dicionário de princípios jurídicos. Rio de Janeiro: Elsevier, 20 I I .

ANDRADE, Maria Inês Chaves de. A fraternidade como direito fundamental entre o ser e o dever ser na dialética dos opostos de Hegel. Coimbra: Coimbra Editora, 2010 .

ARAGÃO, Alexandra. Desenvolvimento sustentável em tempo de crise e em maré de simplificação. Fundamento e limites da proibição de retrocesso ambiental. In: CORREIA, Fernando Alves; MACHADO, Jonatas E. M.; LOUREIRO, João Carlos. (org.). Estudos em homenagem ao Prof. Doutor José Joaquim Gomes Canotilho. Vol. IV. Coimbra: Coimbra Editora, 2012.

BECK, Ulrich. A sociedade do risco: rumo a uma outra modernidade. São Paulo: editora 34, 2010. 
BOFF, Leonardo. Ética e Ecoespiritualidade. Petrópolis: Vozes, 2011 I.

BOTELHO, Marcos César. A legitimidade da jurisdição constitucional no pensamento de Jürgen Habermas. São Paulo: Saraiva, 20 I 0.

BRASIL. Constituição Federal de 1988. Disponível em: <www.planalto.gov.br>. Acesso em: 2 ago. 2017.

. Lei 4.717 de 29 de junho de 1965. Regula a ação popular. Disponível em: <www. planalto.gov.br>. Acesso em: 10 ago. 2017.

. Lei 7.347 de 24 de julho de 1985. Disciplina a ação civil pública de responsabilidade por danos causados ao meio-ambiente, ao consumidor, a bens e direitos de valor artístico, estético, histórico, turístico e paisagístico (VETADO) e dá outras providências. Disponível em: <www.planalto.gov.br>. Acesso em: 10 ago. 2017.

. Lei 13.105 de 16 de março de 20 I5. Código de processo civil. Disponível em: <www.planalto.gov.br>. Acesso em: 2 ago. 2017.

. Supremo Tribunal Federal. Arguição de Descumprimento de Preceito Fundamental n. I0I/DF. Relatora: Min. Cármen Lúcia Antunes Rocha. Publicado no DJ de 4/6/2012. Disponível em: <http://redir.stt.jus.br/paginadorpub/paginador.jsp?doc $\mathrm{TP}=\mathrm{AC} \& d o c \mid \mathrm{D}=629955>$. Acesso em 15 ago. 2017.

CÂMARA, Alexandre Freitas. Lições de Direito Processual Civil. Vol. I. 18 ed. São Paulo: Lumen Juris, 2008.

CANOTILHO, José Joaquim Gomes. Direito constitucional ambiental português: tentativa de compreensão de 30 anos das gerações ambientais no direito constitucional português. In: CANOTILHO, José Joaquim Gomes; LEITE, José Rubens Morato (orgs.). Direito Constitucional Ambiental Brasileiro. 4a ed. São Paulo: Saraiva, 20I I. 2003.

. Direito Constitucional e teoria da Constituição. $7^{\mathrm{a}}$ ed. Coimbra: Almedina,

CENTRO DE INFORMAÇÃO DAS NAÇÕES UNIDAS RIO DE JANEIRO (UNICRIO). A ONU e o meio ambiente. UNIC Rio de Janeiro - Centro de Informação das Nações Unidas Rio de Janeiro. Rio de Janeiro. Disponível em: <http://unicrio.org.br/a-onu-em-acao/a-onu-e-o-meio-ambiente/>. Acesso em: 8 Ago. 2017. 
DIDIERJUNIOR, Fredie; BRAGA, Paula Sarno; OLIVEIRA, Rafael Alexandria de. Curso de direito processual civil: teoria da prova, direito probatório, decisão, precedente, coisa julgada e tutela provisória. Vol. 2. 10 ed. Salvador: Editora Juspodivm, 2015.

DWORKIN, Ronald. Levando os direitos à sério. Trad. e notas por Nelson Boeira. São Paulo: Martins Fontes, 2002.

FIORILLO, Celso Antonio Pacheco. Curso de Direito Ambiental Brasileiro. 2a Ed. São Paulo: Saraiva, 200I.

GOMES, Ariel Koch. Natureza, Direito e Homem: sobre a fundamentação do Direito do Meio Ambiente. Porto Alegre: Livraria do Advogado, 2013.

GOMES, Carla Amado. Risco e modificação do acto autorizativo concretizador de deveres de protecção do ambiente. Coimbra: Coimbra Editora, 2007.

Risco tecnológico, comunicação do risco e direito a saber. In: Direito(s) dos riscos tecnológicos. Coord. Carla Amado Gomes. AAFDL. Lisboa: 2014.

GOUVEIA, Lúcio Grassi de. O dever de fundamentação das decisões judiciais e o novo código de processo civil brasileiro. In: CARVALHO FILHO, Antônio; SAMPAIO JR., Herval. (Orgs.). Os juízes e o novo CPC. Salvador: JusPodivm, 2017.

HABERLE, Peter. Hermenêutica Constitucional, A sociedade aberta dos intérpretes da Constituição: Contribuição para a Interpretação Pluralista e 'Procedimental' da Constituição. Trad. Gilmar Ferreira Mendes. Porto Alegre: Ed. Sergio Antonio Fabris, 1997.

JONAS, Hans. O princípio-responsabilidade. Ensaio de uma ética para a civilização tecnológica. Trad. Marijane Lisboa, Luiz Barros Montez. Rio de Janeiro: Contraponto; 2006.

MARINONI, Luiz Guilherme. Teoria geral do processo. Curso de processo civil. 3. ed. rev. e atual. São Paulo: Revista dos Tribunais, v. I , 2008.

MENDES, Gilmar Ferreira; BRANCO, Paulo Gustavo Gonet. Curso de Direito Constitucional. 9. ed. São Paulo: Saraiva, 2014.

MIRANDA, Jorge. Teoria do Estado e da Constituição. Coimbra: Coimbra Editora, 2011 . 
NEVES, Daniel Amorim Assumpção. Manual de Direito Processual Civil. Volume Único. 8 ed. Salvador: Editora Juspodivm, 2016.

NOVAIS, Jorge Reis. Direitos fundamentais e justiça constitucional em estado de direito democrático. Coimbra: Coimbra Editora, 2012.

. Direitos sociais: teoria dos direitos sociais enquanto direitos fundamentais. Coimbra: Wolters Kluer/Coimbra, 2010.

OST, François. A natureza à margem da lei: a ecologia à prova do direito. Lisboa: Piaget, 1995.

SARLET, Ingo Wolfgang; FENSTERSEIFER, Tiago. Estado Socioambiental e Direitos Fundamentais. Ingo Wolfgang Sarlet (org.). Porto Alegre: Livraria do Advogado, 2010.

. Princípios do direito ambiental. São Paulo: Saraiva, 2014.

Recebido em: II/09/2017

Aprovado em: 16/09/2017 